\title{
Politeness Principle in the Translation of Business Letters*
}

\author{
Tao Zhang \\ School of Translation and Interpretation, Qufu Normal University, Rizhao, Shandong, China \\ Email: royalchang@126.com
}

\begin{abstract}
As the primary form of business communication, business letters play an indispensable role in business activities and contribute considerably to the rapid development of international trade and business. Therefore, the translation of business letters seems critical to the successful communication. Business letters are very formal writing and they observe politeness principle strictly in order to maintain and enhance a good rapport with business partners. So the translation of them needs to consider both English and Chinese politeness principles, which are compared in this paper and politeness equivalence in translation is proposed. Some translating methods are suggested as well.
\end{abstract}

Index Terms-Politeness Principle, equivalence, business letters translation

\section{INTRODUCTION}

With the development of economic globalization and the expansion of transnational corporations, the cooperation and trade between China and other countries are booming and deepening. China, the largest exporter and the largest market in the world, is conducting an unprecedented exchange with the world. As the primary form of business communication, business letters play an indispensable role in commercial activities and contribute considerably to the rapid development of international trade and business. Therefore, a well-translated business letter counts much in international business. Business letters are very formal writing and they observe politeness principle strictly in order to maintain and enhance a good rapport with business partners. In order to achieve the equivalent effect of politeness in the translation of business letters, translators need to get familiar with the politeness principles in both Chinese and English cultures.

\section{Politeness In Both ENGLish AND Chinese Cultures}

As an important part of pragmatic study, researches on politeness have been conducted for a long time. Many scholars proposed their own theories from different perspectives. Grice's Cooperative Principle (CP), Leech's Politeness Principle and Brown and Levison's face-saving view are all influential theories concerning this topic and have made great contribution to the development of pragmatic study.

Based on the theories of western scholars and with the combination of Chinese culture, Chinese researchers have developed Chinese Politeness Principle. Gu Yueguo, the most influential scholar in this area, has summed up the essential elements of Chinese "limao" as the following four notions: respectfulness, modesty, attitudinal warmth, and refinement $(\mathrm{Gu}, 1990)$. According to the four notions of Chinese politeness, $\mathrm{Gu}$ (1990) proposed four maxims of Politeness Principle: the Self-denigration Maxim, the Address Maxim, the Tact Maxim and the Generosity Maxim.

\section{A. Politeness in English Culture}

\section{Grice's Cooperative Principle}

In a 1975 article entitled Logic and Conversation, the American philosopher Paul Grice pointed out that an utterance can imply a proposition (i.e., a statement) that is not a part of the utterance and that does not follow as a necessary consequence of the utterance. Grice called such an implied statement an implicature. In order to explain how the speaker can convey more than what is said and how the hearer can arrive at the speaker's meaning, Grice highlighted that human beings communicate effectively because they are by nature helpful to each other. So based on the concept of implicature, he proposed Cooperative Principle which are the mechanisms or assumptions governing the production and comprehension of the implied statements.

The Cooperative Principle consists of four conversational maxims. They are: (1) Maxim of Quantity. Each participant's contribution to a conversation should be just as informative as is required. (2) Maxim of Quality. Each participant's contribution should be truthful and based on sufficient evidence. (3) Maxim of Relevance. Each participant's contribution should be relevant to the subject of the conversation. (4) Maxim of Manner. Each participant's contribution should be expressed in a reasonably clear fashion; that is, it should not be vague, ambiguous or excessively wordy. 
Generally speaking, these maxims specify that in order to converse in a maximally efficient, rational, cooperative way, participants should speak sincerely, relevantly and clearly with sufficient information provided.

Although Grice's CP helps to explain the relationship between literal meaning and implicature, it does not tell us why people violate those maxims so often. It gives rise to Leech's Politeness Principle, a supplement to CP.

\section{Leech's Politeness Principle}

Cao (1998) points out that the maxims in CP are not always strictly observed; rather, for various reasons they are often violated. Some of these violations can be explained by Grice's conversational implicature. But there are still some other violations that can not be satisfactorily illustrated by Grice's theory. So it is found that CP alone can not fully explain how people talk. It does not tell us why people are often so indirect in conveying what they mean. It is either not good enough to explain what is the relation between sense and force when non-declarative types of sentences are being considered. This is where Politeness Principle comes in. In 1983, Geoffrey N. Leech, the famous British linguist, proposed the Politeness Principle and tried to offer some satisfactory answers to the unsolved questions. Leech believes the main reason that why people violate Cooperative Principle deliberately is they take politeness into consideration.

(1) Parent: Someone's eaten the icing of the cake.

Son: It wasn't me. (Cao, 1998)

In this dialogue, the parent violated the maxim of quantity because he just said "someone" had eaten the icing of the cake instead of scolding the child for that. The reason why he did so is he did not want to embarrass his child, or he wanted to be polite.

For another example, if you want someone to close the door, you could in theory use any of the following sentences.

(2) Shut the door!

I wonder if you would mind shutting the door.

It's so cold in here. (ibid)

But in practice, the first, a direct command, is seldom used because it seems somewhat rude.

Politeness Principle seems to have a higher regulative role than cooperative principle in that it helps to maintain the friendly relations which are required for smooth and effective communication. This is especially true in some cases, e.g. when we want to get our hearers to do something for us.

Humans everywhere ten to be polite in similar ways, based on two basic social requirements: "No criticism" and "No interference". Humans want to be approved of, and they do not want to be imposed upon. Consequently, anyone with social know-how will minimize criticism of others and will avoid interfering with their liberty, at least overtly. These requirements of "No criticism" and "No interference" have an effect on language. Any criticism or interference will be a social risk. Therefore, speakers/writers have to balance up the advantages and disadvantages of "straight talking".

As a supplement to CP, PP has six maxims. Leeeh proposes these maxims to explain how politeness is manifested. When stating his maxims, two terms "self" and "other" are applied since politeness is concerned with a relationship between at least two participants."Self" is used to refer to the speaker and "other" to the hearer or a third party in a conversation.

Maximize (other things being equal) the expression of polite beliefs;

Minimize (other things being equal) the expression of impolite beliefs.

(i) Tact maxim

(a) Minimize cost of others;

(b) Maximize benefit to others.

(ii) Generosity Maxim

(c) Minimize benefit to self;

(d) Maximize cost to self.

(iii) Approbation Maxim

(a) Minimize dispraise of others;

(b) Maximize praise of others.

(iv) Modesty Maxim

(a) Minimize praise of self;

(b) Maximize dispraise of self.

(v) Agreement Maxim

(a) Minimize disagreement between self and others;

(b) Maximize agreement between self and others.

(vi) Sympathy Maxim

(a) Minimize antipathy between self and others;

(b) Maximize sympathy between self and others. (Cao, 1998)

Politeness Principle provides us a standard for dealing with interpersonal relations. The observation of the above maxims can promote the success of communication. The PP is instructive in the felicitous choice of words in the writing of business letters. Everyone likes to enjoy the due respect of others. If the caring and respect for your business partner is duly conveyed in your letter, they will feel pleased and the cooperation is likely to be successful. On the contrary, if your partner is hurt by your letter, there will be some negative influence on your relations, even the 
cooperation will be put in danger.

\section{Brown and Levison's face-saving view}

Politeness can also be interpreted as "the expression of the speakers' intention to mitigate face threats carried by certain face threatening acts toward another." (Mills, 2003, p.6) Politeness consists of efforts to save face for another. What does "face" mean here? There are expressions like "losing face" and "saving face". It is believed that the concept of face is Chinese in origin and many languages have this term that metaphorically means "prestige, honor or reputation". Goffman (1955, p.213) offered us a more detailed definition: The term face may be defined as the positive social value a person effectively claims for himself by the line others assume he has taken during a particular contact. Face is an image of self delineated in terms of approved social attributes.

Brown and Levinson expanded Goffman's concept of face to their politeness theory and made it the core of their politeness framework, which falls into positive face and negative face. Speakers concern both "positive face", the need for solidarity with others, and "negative face", the need for freedom from imposition by others.

\section{B. Politeness in Chinese Context}

Politeness is universal to every social group, but one politeness principle can not be universally applied to any society. The politeness principle is affected by different cultures. Sometimes what the Chinese people considered to be polite may not be the same in western culture. Politeness has the same social functions in both Chinese and Western cultures, and common polite languages in these two cultures are almost the same, but they are different in practical use. These differences often become the source of pragmatic failures in intercultural communication. So it is advisable to discuss the politeness principle in Chinese context.

The concept of Chinese politeness "li" can be traced back to ancient time when Confucius (551-479 B.C.), a great Chinese philosopher and thinker, spared no efforts to restore the social hierarchy and order of the slavery system of Zhou Dynasty. As was expected in ancient China, "li" is hoped to bear the duties of enhancing social harmony and lessening interpersonal tension or conflict in modern Chinese.

\section{Chinese Politeness Principle}

During the past hundreds of years, the ancient concept of "li" has eventually evolved into "limao" of today in China. The core of Chinese politeness or limao is "self-denigration and other-respecting". Gu Yueguo, the most influential scholar in this area, has summed up the essential elements of "limao" as the following four notions: respectfulness, modesty, attitudinal warmth, and refinement (Gu, 1990).

Based on the four notions of Chinese politeness, $\mathrm{Gu}$ proposed four maxims of Politeness Principle: the Self-denigration Maxim, the Address Maxim, the Tact Maxim and the Generosity Maxim. According to the notions of respectfulness and modesty, the Self-denigration Maxim has two submaxims: denigrate self and elevate others. If anyone breaks the maxim of denigrating self, he/she will be considered as being impolite or rude. Meanwhile, if anyone breaks the maxim of elevating other, he/she will be considered as being arrogant or self-conceited. According to the notions of respectfulness and attitudinal warmth, the Address Maxim requires the speaker to select an appropriate address term for the conversational partner. This maxim helps to "establish or maintain social bonds, strengthen solidarity, and control social distance" (Gu, 1990, p.246) since the act of addressing involves recognition of the conversational partner's social status and identification of the social relation between them. It seems rude or brings about the destruction of social order if addressing terms are misused. As a modified version of Leech's, Gu's Generosity and Tact Maxims are two complementary maxims, whose underlying notions are attitudinal warmth and refinement. Under the two maxims, the speaker tries to maximize benefit to other (in compliance with the Generosity Maxim) while the hearer tries to minimize cost to other (in compliance with the Tact Maxim). Breaking the maxims would risk being considered as stingy and greedy respectively.

\section{Chinese concept of face}

Mianzi is regarded as the core part of Chinese politeness. Mao defines mianzi as "prestige, or the respect of the group for a man with a good moral reputation." The differences between Chinese face and Western face are summarized below.

First, their connotation is different. From their definitions we can find out that self-image is the center of Brown and Levinson's concept of face while public- image is the center of Chinese face. The concept of western face is based on the personal values to which Western culture attaches great importance. It puts emphasis on the individual's desire and wants and is free from any external pressure or communal judgment. While Chinese face refers to the reputation or prestige gained from other members of the society. It is closely related to the views and judgments of the community.

Second, their contents of face are different. Gu noted that negative face in the western notion cannot be applied to the Chinese concept of face since acts threatening the interlocutor's negative face, such as offering, inviting and promising, will not be considered as offending a Chinese's freedom, but as sincere behaviors. According to Brown and Levinson's negative face refers to a person's need to be autonomous from others while the Chinese mianzi refers to a person's desire for public acknowledgement of their prestige or reputation. Mianzi is originated from the Confucian tradition that deemphasizes individuals and subordinates them to the group, unlike individuals that seek freedom in the western culture.

\section{Politeness EQuivalenCE IN THE TRANSLATION OF BUSINESS LETTERS}


As a major tool of business communication, business letters attach great importance to politeness. Politeness is an important feature and basic requirement for business letters. The task of a translator is to fully convey the politeness of the source text in the target text on the basis of Western and Chinese Politeness Principles so as to achieve the politeness equivalence.

\section{A. Politeness Equivalence in Translation}

As a significant part of pragmatic study, politeness principle exerts remarkable impact on the success of communication. Meanwhile, politeness is also a concept containing rich cultural connotations. The different cultural backgrounds bring about a certain type of social norms, of course politeness principle being a part of it, with their own distinct features. Translators must be well aware of the cultural differences between source language and target language so as to achieve equivalent effect.

We have mentioned in chapter two that to achieve equivalent effect is the ideal goal of translation. When politeness theory is applied to translation studies, the notion of politeness equivalence is put forward. Politeness equivalence, first proposed by House, is one of the critical factors to be taken into account in evaluating whether a translation is functionally equivalent. As the major part of pragmatic equivalence, politeness equivalence requires the translator, based on the features of the language systems of both source and target language, to reproduce the equivalent politeness effect in the target text as that in the source text. It includes two criteria for evaluating whether the equivalent effect has been achieved: politeness scale and politeness system. Please look at the following example.

(3) 由于原材料成本涨价, 我们须提价 $3 \%$ 。

a. Due to the rising cost of raw materials we must raise our price by $3 \%$.

b. Due to the rising cost of raw materials we have to raise our price by $3 \%$.

c. Due to the rising cost of raw materials we are reluctantly compelled to our price by $3 \%$.

(Liu, 1999)

Although the three translations convey the similar meaning, they differ from each other in politeness degree. The translation of “须” is the key point. Version A, literally equaling “须” with "must”, seems faithful to the original text but it is too tough to express the original intention of the writer. Version B is better because it sounds moderate. Version $\mathrm{C}$ fully observes the politeness principle and successfully conveys the intention of the writer: I am sorry but we have no choice except increasing the price. And the equivalent effect in politeness is achieved.

\section{B. Politeness in E-C Translation}

When English business letters are translated into Chinese, the translation must conform to Chinese Politeness Principle. The following strategies are recommended to achieve the politeness equivalence.

\section{Self-denigration and Others-respecting Maxim in the translation of pronouns}

Chinese politeness is characterized by the notions of respectfulness and modesty, which is demonstrated in Self-denigration and Others-respecting Maxim. It is quite similar to the Modesty Maxim and Approbation Maxim in Leech's PP. Both of them require the writer to minimize praise and maximize dispraise of self and maximize praise and minimize dispraise of others.

It is the custom of Chinese people to use humble terms to refer to self and to use language that is more respectful to address others in communication. The violation of this maxim will be interpreted as being arrogant and self-conceited. But in English there are simply the pronouns like "you" and "I" in a bilateral communication. So in the translation of pronouns used in business letters, in order to achieve politeness equivalence, "you" or "your" is usually translated into “您（nin）”or “贵” to show the esteem for your partner while “I”or “my” is normally translated into “敉” or “我” to show your humbleness. The following two examples demonstrate this.

(4) We are pleased to know that you are planning to visit our company on March 8.

我很高兴得知您打算在 3 月 8 日光临敉公司。

(5) The UK Chamber of Commerce has advised us to get in touch with you concerning digital cameras.

英国商会建议我们就数码相机事宜与贵方联系。

In the above examples, the writer use “敉公司” to refer to “our company” and “贵方” to refer to “you” respectively. In this way, the respect and sincerity of the writer is fully conveyed, the politeness equivalence has been achieved and the distance between the two parties is narrowed. It will be very helpful to establish a mutual trust business relation.

\section{The Address Maxim in the translation of address}

According to the notions of respectfulness and attitudinal warmth, the Address Maxim requires the speaker to select an appropriate address term for the conversational partner. This maxim helps to "establish or maintain social bonds, strengthen solidarity, and control social distance" (Gu, 1990, p.246) since the act of addressing involves recognition of the conversational partner's social status and identification of the social relation between them. It seems rude or brings about the destruction of social order if addressing terms are mistranslated. Chinese Address Maxim is similar to the Tact and Modesty Maxims of Leech's PP. Both Chinese and English writers can use address terms to show their respect towards others and denigration of themselves. In business letterss, address mainly appears in the salutation part.

"Dear" is usually used in the address because it is an important marker of politeness in English writing. "Dear Sirs/Madams” is often used when the writer does not know the name of the specific receiver. Its translation “敬启者”, 
which means "paying tribute to the person who reads this letter", is equivalent in function and meaning and fully conveyed the respect of the writer. If the writer gets to know the name of the recipients, "Dear Mr./Mrs./Ms." is normally employed. On this occasion, the translator can not render "dear" into “亲爱的” literally, although it is semantically right. Here "dear" is just a marker of politeness instead of a demonstration of proximity in English business letters. It is better to be translated into “尊敬的（respectful）先生/女士” or simply “致...先生/女士”.

\section{The translation of conciseness and formality}

Conciseness and formality are the important features of business letters. So the translator has to produce the same effect in text so as to achieve politeness equivalence. Please look at the following examples and compare the two versions of translation.

(6) Please extend your offer for three days.

a. 请将你们的报盘延长三天。

b. 请将你方报盘展期三天。

(7) The offer is subject to the good being unsold on receipt of your reply.

a. 这个报盘以收到你们的答复时货还没有卖掉为有效。

b. 此盘以你方复到时货未售出为有效。

(8) What do your insurance clauses cover?

a. 你们的保险条款包括哪内容。

b. 你们的保险条款中有哪些险别。

(9) We are pleased to advise you that the captioned goods were shipped yesterday Per S. S. "Da Qing".

a. 很高兴通知你方，标题中提到的货物昨大已经由“大庆号” 轮船装出。

b. 兹通知，标题货物已于昨日由“大庆” 轮装出。( Du, 2005: 79)

In the examples above, we can find out that the latter versions of translation are usually short and professional because terms are used.

\section{The translation of other markers of politeness}

Tact and Modesty Maxims in Western culture and the Self-denigration and others-respecting Maxim in Chinese culture are the basis of politeness principle. Besides what we have mentioned, there are still some other politeness makers reflecting those maxims. Translators have to bear them in mind and apply them correctly according to the specific context. Here are some examples.

(10) Could you please send us a copy of your latest catalogue?

可否惠寄（赠）我方一份贵公司的最新商品目录?

(11)Yours faithfully Dennis Jackson

丹尼斯 杰克逊 谨 (敬) 上

(12) Would you agree to our suggestion that future clients should call you?

未知可否让其他客户来电垂询?

(13) I enjoyed meeting you...

很荣幸与您见面

(14) We enclose our new catalogue and price list.

谨附上新的商品目录和价格表。

From the above examples, we can find out that there are many Chinese words indicating the politeness, such as “谨/ 敬” “惠” “荣幸” and so on. Meanwhile, some English markers can also be found from these examples, such as "should" "could" "would like" and other modal words.

\section{Politeness in C-E Translation}

When Chinese business letters are translated into English, the translation must conform to English Politeness Principle. The following strategies are recommended to achieve the politeness equivalence.

\section{The translation of Chinese address}

Chinese people tend to use titles like “李校长” “张局长” “杜经理”to address others. But these addresses “Principal Li" "Bureau director Zhang" and "Manager Du" are seldom seen in English business letters. The translator can just render them into "Mr. Li"'"Ms. Zhang" and "Mr. Du".

\section{The translation of soft and euphemistic tone}

As an important way of communication, business letters perform dual functions: one is to transmit messages; the other is to enhance the relations between business partners. The second function of business letter needs the translator/writer to use polite, soft and euphemistic language. Any blunt or arrogant expression must be avoided so as not to make the reader lose face, then eventually harm the business relations. How can a translator produce politeness equivalence? The tact and modesty maxims of Leech serve as a good guideline. Please look at the following examples.

(15) 你方价格大大低于我方成本, 我们不能按你价成交。

a. We can not entertain business at your price, since it is far below our cost.

b. We are not in a position to entertain business at your price, since it is far below our cost. 
“不能” in the Chinese version is a direct refusal. So the literal translation of it into "can not” in version A sounds imposing and not polite enough. This translation is too blunt and hard to accept for the reader. Version B selects a soft expression "not in a position" instead of using the direct refusal. It helps to save the reader's face and sounds more agreeable.

（16）相信贵方会按期发货，因为迟误势必会给我们造成很大不便和经济损失。

a. We believe you will see to it that the order is shipped within the stipulated time, as any delay would cause us great inconvenience and financial loss.

b. We trust you will see to it that the order is shipped within the stipulated time, as any delay would cause us no little inconvenience and financial loss.

In this example, it is better to translate “相信” into "trust” than "believe” because it gives a stronger sense of trust and can narrow the distance of the reader and the writer. In version B, “很大不便” was translated into “no little inconvenience", which rounds about and sounds soft. It is better than expressing directly.

Besides, according to the Tact and Sympathy Maxim of PP, the translator had better take a "you-attitude" in their translation. "You-attitude" requires the translators to express their consideration for the benefits of the reader. It makes the translation soft, easy to be accepted and helps to enhance the business relations. For example,

(17) 贵方如想获得大笔交易必须降价 $2 \%$ 。

You could benefit from a higher sale with a little concession, say, a $2 \%$ reduction.

The Chinese version is polite but sounds tough and imposing. The translation softens the tone by showing the consideration for the reader's benefits. Even when one party makes mistakes, the other party should not express his arrogance and sharp criticism, which is impolite and harmful to their cooperation. If the translator can produce a euphemistic version of criticism, it will save the face of the reader and helps to improve their relations. Look at the following examples.

(18) 贵方如想不致声誉受损，必须于今天支付账单。

By sending your check today, you will be able to maintain your good credit reputation.

(19) 贵方来货质量与协议中规定的不符。

It is much to be regretted that the quality of your shipment isn't in conformity with the agreed specification.

(20) 很遗憾, 我方必须取消该货物的订单。

Much to our regret, we have to cancel our order for this good.

Actually, both example (18) and (19) are bound to convey criticism against the reader. But the translator does not stick to the literal meaning of Chinese version but express the criticism in a mild way. The benefits of the reader seem to be fully taken into consideration. Example (20) expresses the refusal by showing sympathy. By using "have to" instead of "can not", the translator makes the refusal easier to be accepted and helps to save the face of the reader.

All those translations successfully achieve the politeness equivalence by observing the maxims of polite principle.

\section{The translation of "请"}

In Chinese, “请”, as a formal word and an important marker of politeness, is usually used to show one's deference when asking for other's help. But in English there are many different expressions containing the meaning of “请” according to different contexts. In order to achieve equivalent effect, the translator must select the most suitable one to meet the requirement of the specific context. Here are several examples.

(21) 请寄来附有最优惠价格的奔驰轿车目录。

We would appreciate your sending us the catalogue of Benz cars with their best prices.

(22) 货已备妥, 等待装运, 请指示。

The goods are nearly ready for dispatch and we should be glad to have your instruction.

(23) 请报椅子的最优惠上海到岸价，同时请报 最早交货期。

It would be appreciated if you could quote your best prices of CIF Shanghai for chairs, and also let us know the earliest possible date you can make shipment.

From the above examples, we can see "we would appreciate. . ", "it would be appreciated (clause)" and "we would be glad to. .." are used to convey the politeness of the writer. Those sentence patterns have actually become programmed structures of indicating respect or esteem of the speaker. All of them are the equivalent expressions of “请”. The translator should be familiar with these patterns and apply them according to the specific context. Here below is another example.

(24) 请帮我订一张由纽约到亚特兰大的飞机票.

A. Please help me book a plane ticket for the trip from New York to Atlanta.

B. I would greatly appreciate your helping me to book a plane ticket for the trip from New York to Atlanta. (Liu, 2002)

In this example, version A is completely correct in grammar and equivalent in meaning. Although "please" is used to indicate politeness, but compared with version B, it sounds not so sincere and soft in tone. It sounds like an order instead of polite request. By using "I would greatly appreciate", version B sounds softer and more agreeable. 


\section{CONCLUSION}

Politeness is a significant part of pragmatic study. It accounts for much in the pragmatic translation of business letters to achieve politeness equivalence in translation. Both Chinese and Western politeness principles provide us with a helpful tool and general guideline. A well-translated business letter can not only convey the necessary messages concerning business activities but also helps to maintain and enhance their pleasant business relations. It helps reduces the disputes and conflicts in business transactions and eventually contributes to the smooth development international trade.

\section{REFERENCES}

[1] Brown, P. and Levinson S. (1987). Politeness: Some Universals in Language Usage. Cambridge: Cambridge University Press.

[2] Cambridge Advanced Learner's Dictionary (2 ${ }^{\text {nd }}$ ed.) (2005) Cambridge: Harvard University Press.

[3] Cao Wutang. (1998). An introduction to linguistics. Jinan: Shandong Education Press.

[4] Du Zhan. (2005). Style Equivalence in E-C Translation of Business Letters. Journal of Shijiazhuang Institute of Railway Engineering. Vol.IV:77-80.

[5] Grice, H. P. (1957). Meaning. Philosophical Review 66: 377-88.

[6] Grice, H. P. (1975). Logic and Conversation. In P. Cole \& J. L. Morgan (eds. ) Syntax and Syntactics: Speech Acts. New York: Academic Press. Pp.41-58

[7] Goffman \& Erving (1955). "On Face-work: An Analysis of Ritual Elements of Social Interaction.” Psychiatry: Journal for the Study of Interpersonal Processes 18 (3), 213-23.

[8] Gu Yueguo. (1990). Politeness phenomena in modern Chinese. Journal of Pragmatics (14): 237-257.

[9] Gu Yueguo. (1992). Politeness, pragmatics and culture. Journal of Foreign Language Teaching and Research 4:10-17.

[10] Leech, G. (1983). Principles of Pragmatics. NewYork: Longman

[11] Li Ming. (2003). Chinese-English Translation for International Business. Beijing: Higher Education Press

[12] Li Tong. (2003). Pragmatic Differences in Politeness Compared between English and Chinese. Journal of Xinzhou Teachers University, (12): 29-31

[13] Liu Fagong. (2002). Exploring into the Principles of Chinese-English Business Translation. Chinese Translators Journal (1): 45-48.

[14] Liu Fagong. (1999). E-C Business Translation Based on the Analysis of the Linguistic Features of Business English. Journal of PLA Foreign Language University. (2): 74-77.

[15] Mills, S. (2003). Gender and Politeness. Cambridge: Cambridge University Press. Reprinted in Goffman (2005, pp. 5-46)

Tao Zhang was born in Jining, China in 1979. He received his Bachelor's degree from Qufu Normal University, China in 2002 and got his Master's degree from Beijing International Studies University, China in 2010. He is currently a lecturer in the School of Translation and Interpretation since 2002. His major field of study is translation studies and business English teaching. 